TAO, Vol. 16, No. 2, 487-511, June 2005

\title{
Regional Spectral Model Simulations of the Summertime Regional Climate over Taiwan and Adjacent Areas
}

\author{
Ching-Teng Lee ${ }^{1, *}$, Ming-Chin $\mathrm{Wu}^{1}$, and Shyh-Chin Chen ${ }^{2}$
}

(Manuscript received 19 November 2004, in final form 19 April 2005)

\begin{abstract}
The National Centers for Environmental Prediction (NCEP) regional spectral model (RSM) version 97 was used to investigate the regional summertime climate over Taiwan and adjacent areas for June-July-August of 1990 through 2000. The simulated sea-level-pressure and wind fields of RSM1 with 50-km grid space are similar to the reanalysis, but the strength of the simulated subtropical high tends to be too strong, resulting in intensified southeasterlies, instead of southwesterlies, over the region of southern to southeastern China. Generally, the simulated precipitation patterns of RSM1 followed those of NCEP reanalysis, but the large-scale southeasterly wind bias was responsible for the precipitation excess over eastern and southeastern China when compared to observations.

For simulation at 15-km grid space over Taiwan (RSM2), the climatology and inter-annual variability of island-mean precipitation agreed well with station observations and were improved from the coarser forcing reanalysis and RSM1. However, the temporal correlation was seasonally and geographically dependent, presumably due to influences from the interaction of the orography and biases of the large-scale circulations. The RSM, although improved from reanalysis, still tends to produce less heavy rainfall days than observations, especially in July and August. In addition, while the typhoon-day composites of sea-level pressure and precipitation reveal poor agreement between the observations and the RSM simulations, RSM2 simulation placed the precipitation center accurately over southwestern Taiwan during non-typhoon days, albeit with weaker amplitude. These results indicate the limitations of the RSM in simulating summertime convective storms and typhoon events in this area.
\end{abstract}

\footnotetext{
${ }^{1}$ Department of Atmospheric Sciences, National Taiwan University, Taipei, Taiwan, ROC

2 USDA Forest Service, Riverside, CA, USA

* Corresponding author address: Dr. Ching-Teng Lee, Department of Atmospheric Sciences, National Taiwan University, Taipei, Taiwan, ROC; E-mail: WUL8306@wu.as.ntu.edu
} 


\section{(Key words: Regional modeling, Region climate, Taiwan climatology, Downscaling)}

\section{INTRODUCTION}

There are many expectations that regional climate models will provide useful added highresolution information from global-scale reanalysis and climate forecasts for regional applications (Lee and Suh 2000; Liu et al. 1994; Nobre et al. 2001; Roads et al. 2003). These regional models have simulated broad scale regional climate very well over East Asian, and American regions. However, on the local scale, such as over the Taiwan area, added skill by the regional model is yet to be proven. It is difficult to develop a regional climate simulation in the Taiwan area, in part due to the complex terrain over the island. The steep Central Mountain Range $(\sim 3 \mathrm{~km}$ high) runs approximately in a north-south direction across the relatively narrow Taiwan Island and produces two distinctly different climatological precipitation patterns over eastern and western Taiwan (Yeh and Chen 1998). It has been shown that the dominant precipitation pattern appears on the prevailing windward side of the mountains, and hence topography plays an important role in inducing these patterns. In addition, Hsu and Chen (2002) pointed out the climatology in Taiwan is affected not only by the regional land-sea contrast and the complex terrain, but also by the large scale East Asian monsoon system.

Juang and Kanamitsu (1994) and Juang et al. (1997) developed the regional spectral model (RSM) at the National Centers for Environmental Prediction (NCEP) based on the global spectral model (GSM). This regional model has been used in various regional climate studies for analyzing characteristics of precipitation (e.g., Chen et al. 1999; Hong and Leetmaa 1999) and regional climate simulation (Roads et al. 2003). Chen et al. (1999) used a nesting of GSM/ RSM to simulate wintertime precipitation in California. The embedded RSM downscaled the global scale variations to regional variations that were much more consistent with regional orography and provided a physical and dynamical extension of the resolvable spectral range to scales way beyond those of GSM. The RSM produced fairly realistic regional precipitation features compared to observations and simulated heavy rainfall events better than the GSM during wintertime. Hong and Leetmaa (1999) showed that RSM simulated well large-scale features and precipitation distribution for different seasons in their three-month simulation, and the daily precipitation variation was reasonable when compared to observations. Chen et al. (2003) used RSM version 96 to downscale the global change scenarios from a Community Climate Model (CCM3) over the Taiwan area during summer (June through August) and winter (December through January). Their results showed simulated current date precipitation patterns similar to observations, but the amount of precipitation was overestimated, especially in wintertime. Recent regional model inter-comparison studies by Takle et al. (1999) and Roads et al. (2003) also show that the RSM has comparable, if not better, skill than many other regional climate models over various areas. These studies have proven that the RSM might be a useful tool for regional climate study over Taiwan, although it may still suffer from the limitations due to imperfect model physics and possible errors introduced by improper nesting procedures. 
The purpose of this study is to simulate a RSM summer climate over the Southeast Asian and Taiwan areas using the RSM with recently improved model physics and modeling algorithm. A brief description of the RSM is given in section 2. Section 3 describes the results of RSM simulation with 50-km resolution (RSM1) over Asia. The simulation with $15-\mathrm{km}$ resolution (RSM2) over Taiwan Island is in section 4. The conclusions are provided in section 5.

\section{MODEL, DATA AND EXPERIMENT DESIGN}

The RSM used in this study is the NCEP version (97v) by Juang and Kanamitsu (1994) and Juang et al. (1997). The RSM is a regional extension of NCEP's GSM, the basic global model used for the NCEP/National Center for Atmospheric Research (NCAR) reanalysis (see Kalnay et al. 1996 for a description of the model physics). The RSM uses the same primitive hydrostatic system of virtual temperature, humidity, surface pressure and mass continuity prognostic equations on 28 terrain-following sigma coordinates as the forcing NCEP reanalysis. Identical GSM model physics, but operated on a different spatial scale, are also used in the RSM. Therefore if the RSM is set up in a way such that the regional forcings are absent, for example, if both the RSM and GSM were run at similar resolutions, their solutions should theoretically be identical. However minor structural differences might prevent this perfect match from happening. For example, the GSM uses divergence and vorticity equations while RSM utilizes momentum equations to simplify the application of lateral boundary condition in a limited area model. The other difference is the spectral representation. Spherical harmonics are used in a GSM, in contrast to the double Fourier representation of the variables deviation about the imposing basic field in a RSM.

We also used a new diffusion scheme, which has been implemented in the RSM (Juang et al. 2005). This new diffusion scheme represents the model horizontal diffusion with full-field second-order equations on pressure surface, which replaced the origin scheme of fourth-order diffusion on sigma surface. Juang et al. (2005) compared simulated wintertime precipitation over Taiwan using two diffusion schemes. They concluded that the diffusion on pressure surface scheme improved the precipitation excess over the mountain area and demonstrated a better simulated pattern when compared to observations, although a slight excess was still evident. The bias over the mountain area in the original scheme was due to the stratification having been artificially diffused and mixed vertically. In this study, the four-time daily triangular truncation 62 (T62) and 28-level NCEP/NCAR reanalysis are used for basic fields which are linearly interpolated at each time-step within each 6-hour nesting interval. The reanalysis is also used as initial condition.

Many observed data sets were used for model validation in this study. In addition to serve as the driving field for the RSM, the NCEP reanalysis was also used to contrast the added regional details as well as the altered large-scale circulation pattern. Three additional data sets at various temporal and spatial scales were used for simulation validation. The first set is the observed precipitation data from the Global Precipitation Climatology Project (GPCP, Huffman et al. 1997) for monthly mean (1990 - 2000) on $2.5^{\circ}$ global grids, and daily mean (1997 - 2000) on $1.0^{\circ}$ global grids. These data were estimated from a combination of low-orbit-satellite 
microwave data, geo-synchronous-orbit-satellite infrared data and rain gauge observations. For higher resolution comparison, we also used precipitation and temperature data from the University of East Anglia's Climatic Research Unit data set CRU TS 2.0 (Mitchell et al. 2004). This data comprises 1200 monthly grids of observed climate for the period 1901 - 2000, and covering the global land surface at 0.5 -degree resolution $(\sim 60 \mathrm{~km})$. Another observed daily precipitation and temperature data set at 21 surface stations and 338 rain gauge stations from the Central Weather Bureau (CWB) covering the island of Taiwan were also used for finer resolution simulation validations (see Fig. 1a for station locations). The gauge stations were compiled from the tipping-bucket rain gauge for rainfall measurements at a resolution of 0.5 $\mathrm{mm}$. (Chien et al. 2002), and then were binned into the $15-\mathrm{km}$ grids over Taiwan Island.

Two nestings of the RSM simulation were used in this study. Both regional domains are shown in Fig. 1b. The larger domain, RSM1 $\left(101.4^{\circ} \mathrm{E}-117.0^{\circ} \mathrm{E}\right.$ and $\left.10.9^{\circ} \mathrm{N}-36.2^{\circ} \mathrm{N}\right)$, has Mercator projection centered at $\left(23.5^{\circ} \mathrm{N}, 121^{\circ} \mathrm{E}\right)$ with $50-\mathrm{km}$ grid spacing. The smaller domain, RSM2 $\left(117.2^{\circ} \mathrm{E}-125.1^{\circ} \mathrm{E}\right.$ and $\left.19.9^{\circ} \mathrm{N}-27.0^{\circ} \mathrm{N}\right)$, has a $15-\mathrm{km}$ grid space. The RSM simula-

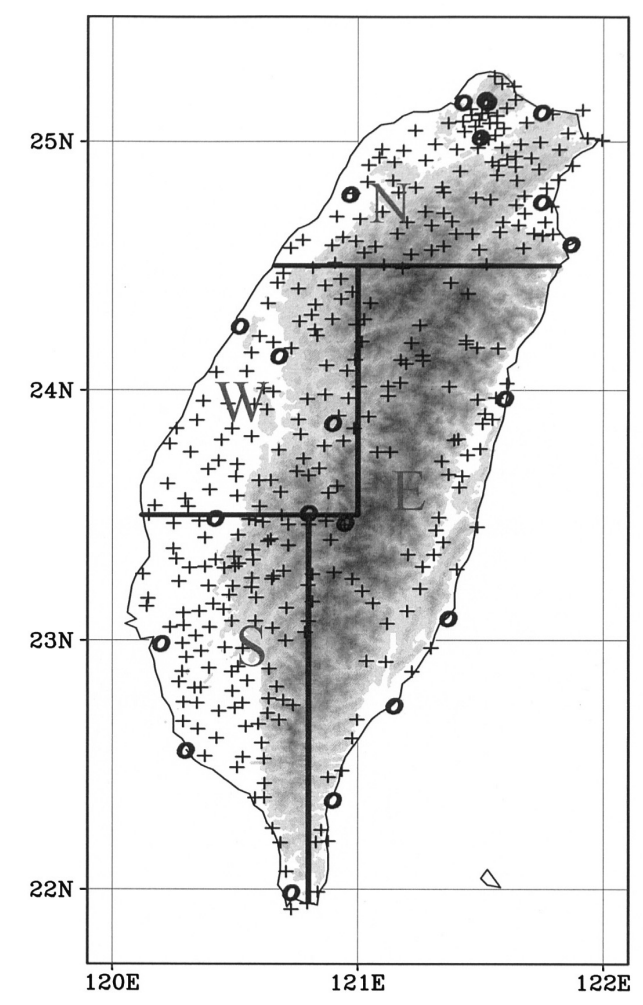

Fig. 1a. Location for 21 surface stations ("o") and 338 rain gauge stations (“+”) over four portioned areas, North (N), West (W), South (S), and East (E), of Taiwan. Terrain height (shaded) starts at $200 \mathrm{~m}$, with shading intervals of $300 \mathrm{~m}$. 
Fig. $1 b$. The domains of RSM1 and RSM2 are centered at Taiwan Island with resolution of $50 \mathrm{~km}$ and $15 \mathrm{~km}$, respectively. The outer domain is for RSM1 and its orography is plotted.

tions were restarted at June 1 each year and were allowed 48 hours for spin up. All runs were a 3-month, June, July and August (JJA), simulation segment for each year from 1990 to 2000. This simulation strategy captured the features during each season and avoided the potential bias of long-term simulation (Chen and Roads 2004). However, we also recognize that, even with this 11 summer-seasons simulation, these results are only barely sufficient for studying the inter-annual regional climate variability.

\section{REGIONAL CLIMATE SIMULATIONS OVER SOUTHEASTERN ASIA (RSM1)}

The 11-year monthly mean sea level pressure (SLP) in June for the simulation, and those from the reanalysis are shown in Fig. 2. The simulated subtropical high over the western Pacific Ocean and the continental low extension are similar to those in the reanalysis, but the RSM shows a local orography-related low pressure feature over Taiwan. However, the simulated magnitudes of the subtropical high and the continental low are somewhat overestimated, and the continental low is extended into the Tibetan Plateau joining the cutoff low over southeastern China. Thus the meridional SLP gradient over the southeastern China and Taiwan areas has been intensified, resulting in stronger southerlies and southwesterlies. These large- 
scale differences between the driving reanalysis and the RSM simulation are believed to be model drift caused by defective physics or imperfect nesting methodology in continuous regional model simulation. The consequence of these large-scale biases in high-resolution simulation will be discussed later.
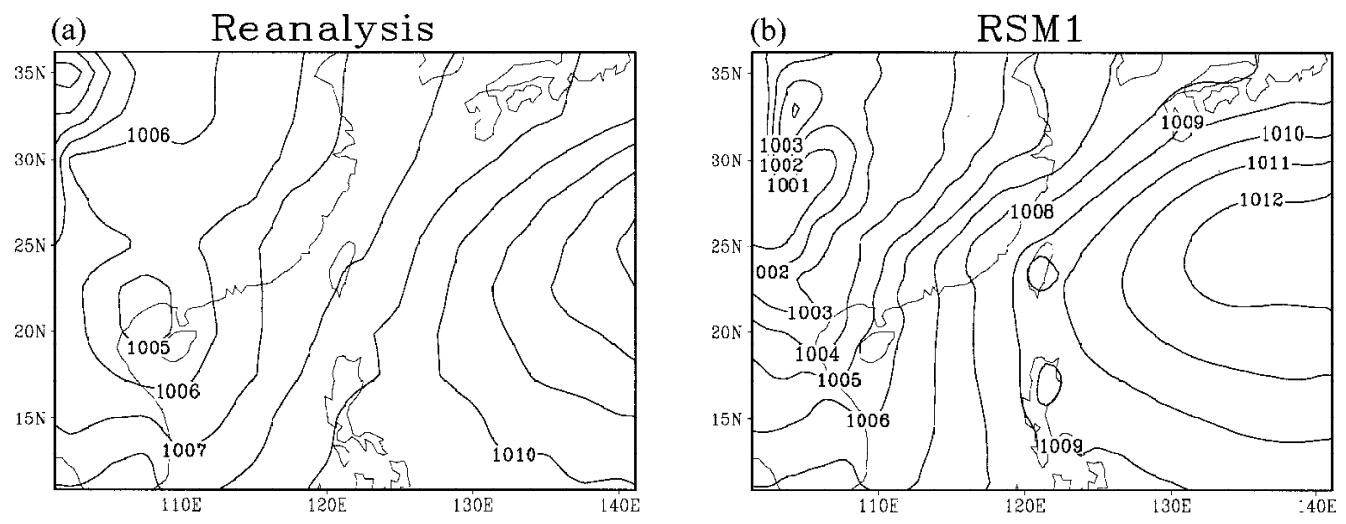

Fig. 2. 11-years averaged monthly-mean June sea level pressure with contour intervals of 1-hPa from (a) NCEP reanalysis, and (b) RSM1.

Figure $3 \mathrm{~b}$ depicts simulated June 850 -mb specific humidity and wind field which is similar to that from reanalysis in Fig. 3a. In the model, however, the subtropical high is much drier, and the wind too strong, as indicated in Fig. 1b when compared to reanalysis. The resulting intensified southwesterlies over southeastern China and the South China Sea are partly related to the overestimated precipitation (will be shown later) in the RSM. Figure 4 shows the June surface air temperature of reanalysis, CRU observations, and RSM simulation. . In a detailed comparison to CRU temperature data, the RSM, due to its more realistic surface orography, captured terrain-induced surface temperature features much better than those by reanalysis. Overall, the RSM reasonably simulated observed large-scale features with detailed regional distribution over land areas. However there are noticeable large-scale biases. July and August also revealed similar results (not shown).

To better understand how RSM simulations are different from the driving reanalysis, we calculated their pattern correlation coefficients for the entire 11-year simulations in Table 1. It is shown that the correlation increases with height for geopotential heights and wind components. This indicates that most of the modification by the RSM occurred near surface, but surface wind variables ( $\mathrm{u} 10 \mathrm{~m}$ and $\mathrm{v} 10 \mathrm{~m}$ ) and temperature (T2 $\mathrm{m}$ ) have less change with the nudging background than the specific humidity $(\mathrm{Q} 2 \mathrm{~m})$. Note that this correlation analysis bears no meaning for the simulation quality, other than indicating how much each variable was modified by the RSM. Without more complete high-resolution data, it is quite difficult to conclude that these additional regional details generated by the RSM are improvements due to the RSM over coarse resolution reanalysis. At present, the best validation data for the regional climate model might still be the rain gauge data for its dense spatial coverage and long-term available 


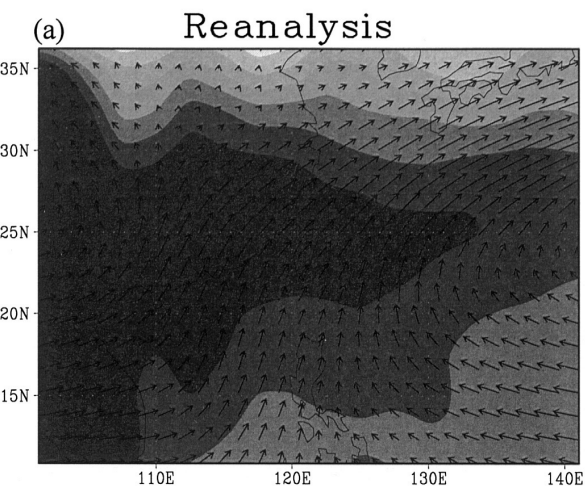

(b)

RSM 1

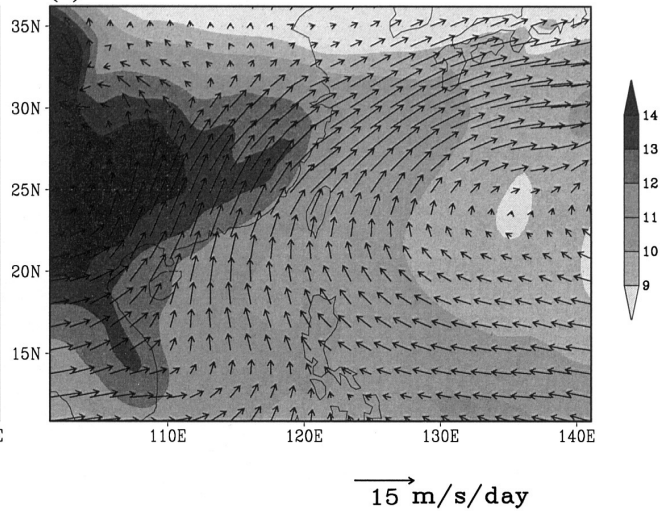

Fig. 3. Same as Fig. 2, except for wind and specific humidity at $850-\mathrm{hPa}$ with shaded interval of $1 \mathrm{gkg}^{-1}$.
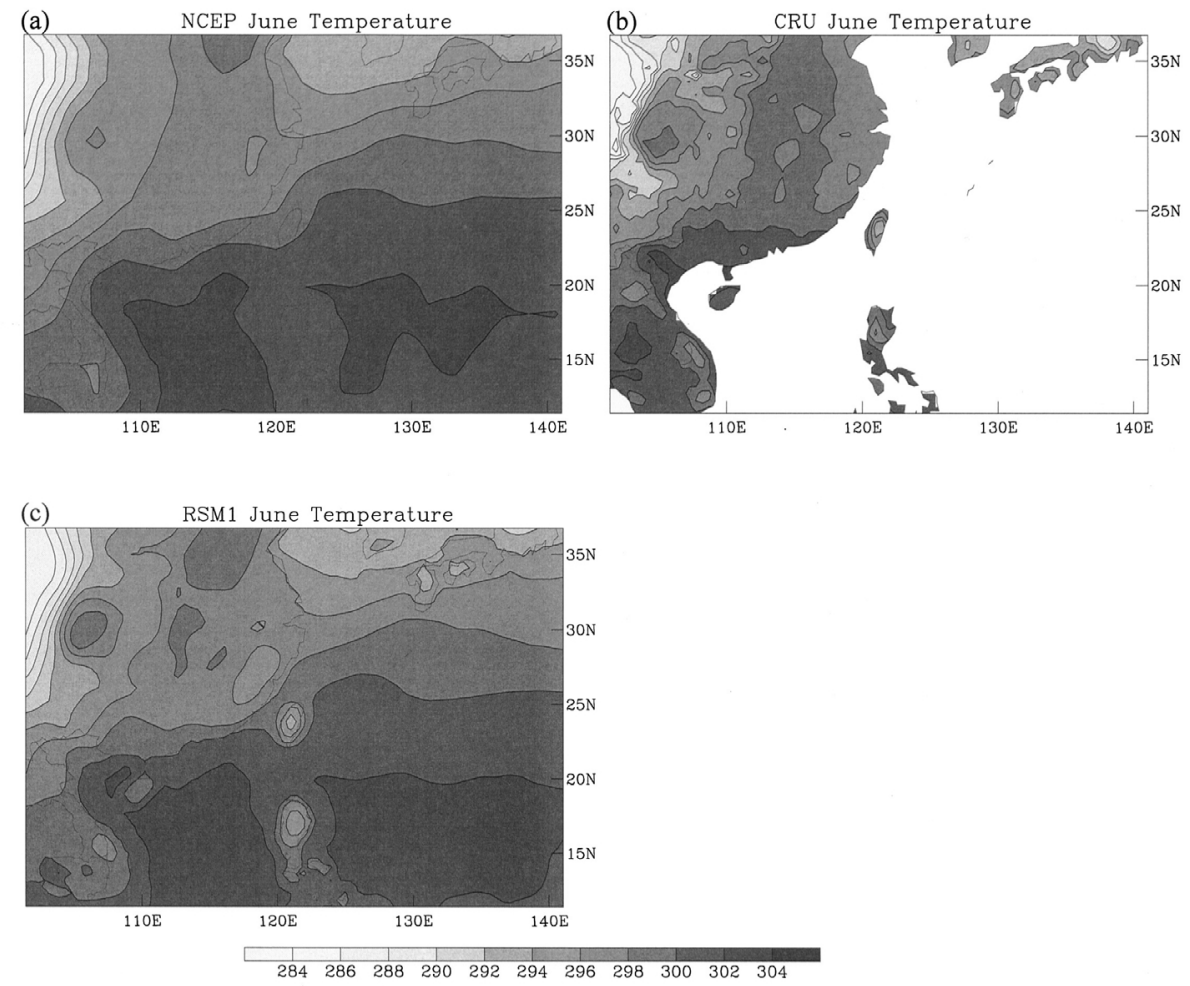

Fig. 4. RSM1 June temperature averaged over 1990 through 2000 for (a) NCEP reanalysis; (b) CRU and (c) RSM1. The temperature shaded intervals are $2 \mathrm{Kday}^{-1}$. 
observations. But unfortunately, the modeled precipitation is also one of the most difficult variables to simulate.

Table 1. Spatial pattern correlation coefficients between NCEP reanalysis and RSM simulation output for 10-meter $\mathrm{u}$-wind $(\mathrm{u} 10 \mathrm{~m})$ and $\mathrm{v}$-wind (v10m), 2-meter temperature (T2m) and specific humidity (Q2 m), sealevel-pressure (SLP), height (HGT), u wind and $\mathrm{v}$ wind.

\begin{tabular}{|c|c|c|c|c|c|c|c|c|}
\hline Pattern Corr. & $\mathrm{u} 10 \mathrm{~m}$ & $\mathrm{v} 10 \mathrm{~m}$ & $T 2 m$ & Q2m & SLP & HGT & $\mathrm{u}$ wind & $v$ wind \\
\hline Surface & 0.85 & 0.81 & 0.84 & 0.74 & 0.89 & rexty & 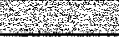 & 3 \\
\hline $\mathrm{Pa}$ & 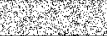 & (2) & W & W & H & 0.89 & 0.81 & 0.78 \\
\hline & 4 & & & & & 9 & 5 & .78 \\
\hline 5 & & & & & 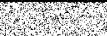 & 0.90 & 35 & 0.80 \\
\hline $500 \mathrm{hPa}$ & & Y. & 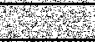 & beterty & N. & 0.91 & 0.88 & 0.83 \\
\hline $300 \mathrm{hPa}$ & 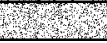 & (Y) & (3) & 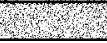 & (3) & 0.94 & 0.91 & 0.86 \\
\hline
\end{tabular}

The June monthly-mean precipitation (from 1990 to 2000) is shown in Fig. 5a for reanalysis, Fig. 5b for GPCP, and Fig. 5c for CRU. Similar to GPCP, CRU precipitation demonstrates heavy rainfall patterns over southeastern China and Kyushu Island of Japan. The reanalysis has shown a somewhat different precipitation pattern from that of GPCP and CRU with a more intense pattern over land, and less over the ocean. RSM1 simulation in Fig. 5d is similar to the reanalysis, but with even more over-estimation over eastern and southeastern China, and greater under-estimation over the ocean. The RSM precipitation depicts more regional detailed distribution. Although the RSM precipitation is overestimated as compared to either CRU or GPCP, it is better than reanalysis in terms of simulating regional maximum centers over the oceanic islands such as Taiwan and Japan. However it is postulated that the wet bias of the RSM simulation may be inherited from the wet initial and forcing circulations of reanalysis.

To compensate for the inherited systematic bias from reanalysis, Figure 5e shows the corrected precipitation pattern after the systematic biases were removed. This simple correction is done by removing precipitation differences between reanalysis and GPCP (Figs 5a, b) from the RSM simulations. Figure 5e shows that the precipitation excess was reduced over southeastern China, but increased over the Taiwan and Japan areas. Rainfall over ocean near Japan was enhanced, and this corrected pattern is slightly closer to GPCP than the original simulation in Fig. 5d.

In July, the precipitation centers of GPCP and CRU (Figs. 6b, c) moved southward to tropical regions, but GPCP has more precipitation over East China, and reanalysis (Fig. 6a) has a similar displacement. However, the reanalysis shows more precipitation over China and therefore it has two relative maximum centers. This pattern is associated with a strong southerly circulation from ocean to land as shown in Fig. 3a, which produces the rainfall excess over South China due to the wind convergence. The RSM simulation (Fig. 6d) inherited and amplified these features from reanalysis with regionally enhanced details over land. The biasremoved precipitation simulation (Fig. 6e) shows that the amount of heavy precipitation is reduced and somewhat more realistic features are revealed over land areas as compared to GPCP, but the precipitation over ocean is still underestimated. 

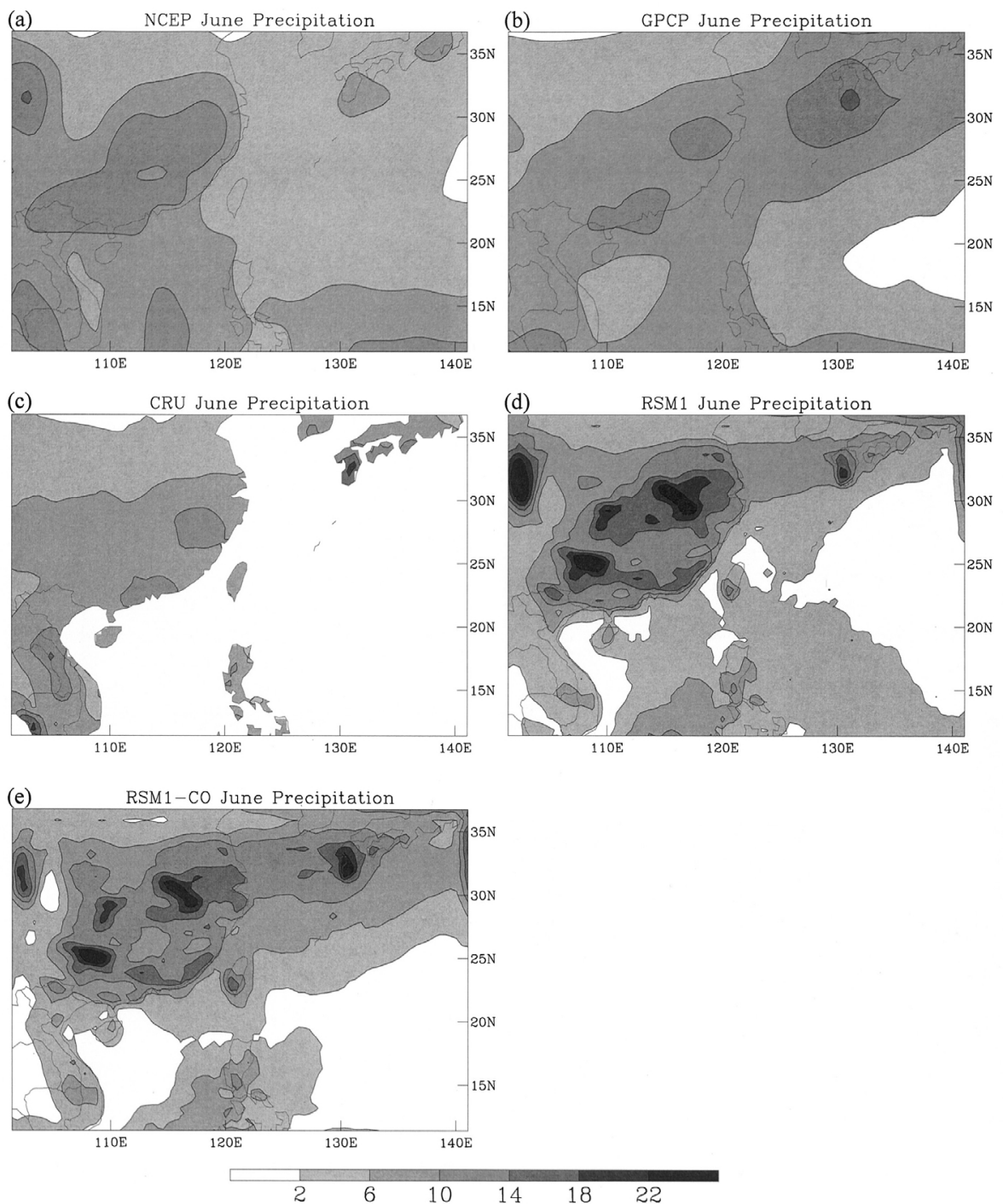

Fig. 5. RSM1 June precipitation averaged over 1990 through 2000 for (a) NCEP reanalysis; (b) GPCP; (c) CRU; (d) RSM1, and (e) RSM1 runs with bias corrected. The precipitation contour intervals are $4 \mathrm{~mm} \mathrm{day}^{-1}$.

In August (Fig. 7) CRU and GPCP show a similar precipitation pattern as that of July, but with a southward displacement. However, reanalysis reveals a heavy rainfall pattern persisting from July through August over eastern and southeastern China. The RSM precipitation is similar to reanalysis but with more intense precipitation over eastern and southeastern China. Overall, the precipitation of GPCP shows an increase over the ocean and a decrease over land 

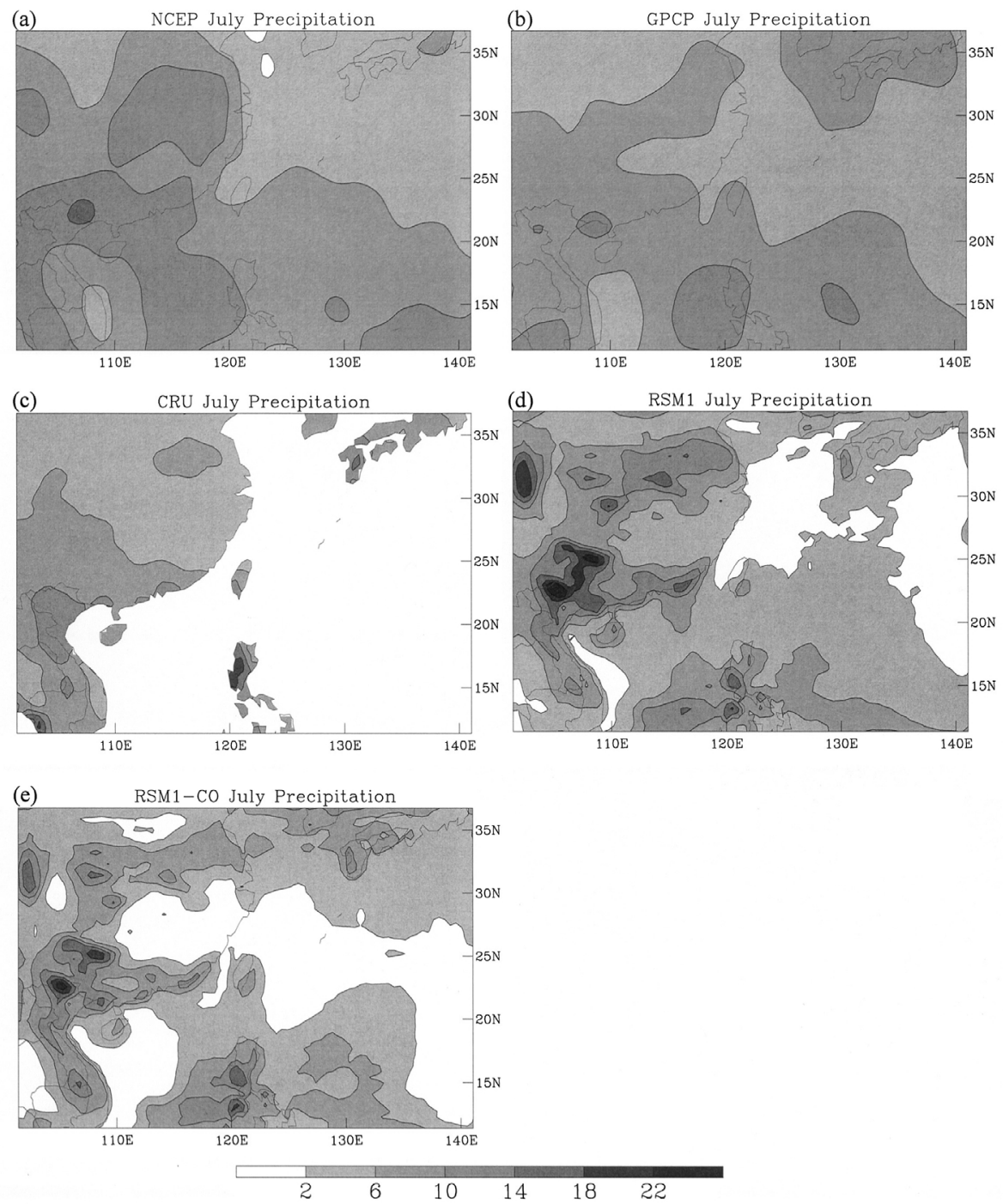

Fig. 6. Same as Fig. 5, except for July.

from July through August, but this is not clearly seen in the reanalysis and the RSM. Furthermore, the RSM simulated precipitation is enhanced over land as compared to reanalysis, and reduced over the ocean. This erroneous pattern is partly due to the spuriously enhanced subtropical high and the deepening of the East Asian low in the RSM, resulting in an increased pressure gradient when compared to reanalysis (Fig. 2). The increase in the zonal pressure gradient enhanced the meridional (southerly) circulation, producing more intense rainfall over land. It is important to bear these large-scale biases in mind when evaluating the ultimate high-resolu- 
tion skill of a regional model using high-resolution observations since many regional features are strongly affected by them.

\section{REGIONAL CLIMATE SIMULATIONS OVER TAIWAN AREA (RSM2)}

The 11-year climatologies of June precipitation and temperature from observations, RSM1 and RSM2 over Taiwan are shown in Figs $8 a$ and $b$. The observations are obtained by binning
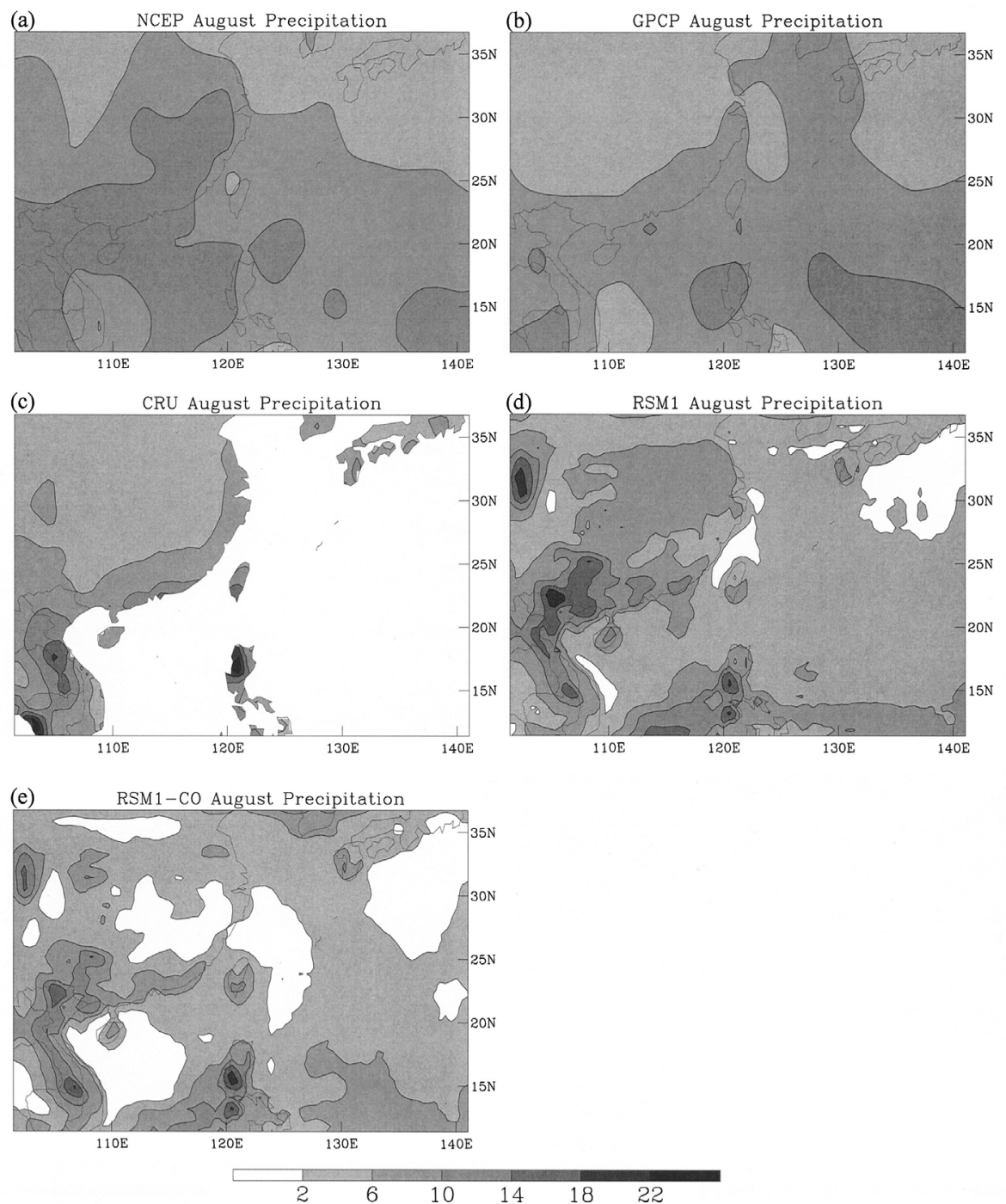

Fig. 7. Same as Fig. 5, except for August. 
all corresponding station data into the model grid boxes. Compared to observed precipitation data (Fig. 8a), RSM1 simulation has displaced major precipitation centers over to Southern Taiwan, and RSM2 improved the precipitation feature over Northern Taiwan but underestimated amplitude for all regional centers. This defect in RSM2 might be due to the use of the over-smoothed second order diffusion scheme in the RSM (Juang et al. 2005). The observed surface temperature (Fig. 8b) has lower values over the entire Central Mountain Range. Note that since there are only 21 available surface stations' data for surface temperature, many mountain areas were void of data. RSM1 shows lower temperature over a broader central Taiwan area but with higher value than that observed. RSM2 show a similar temperature gradient and pattern over Taiwan but with values closer to observations. Since RSM2 has a
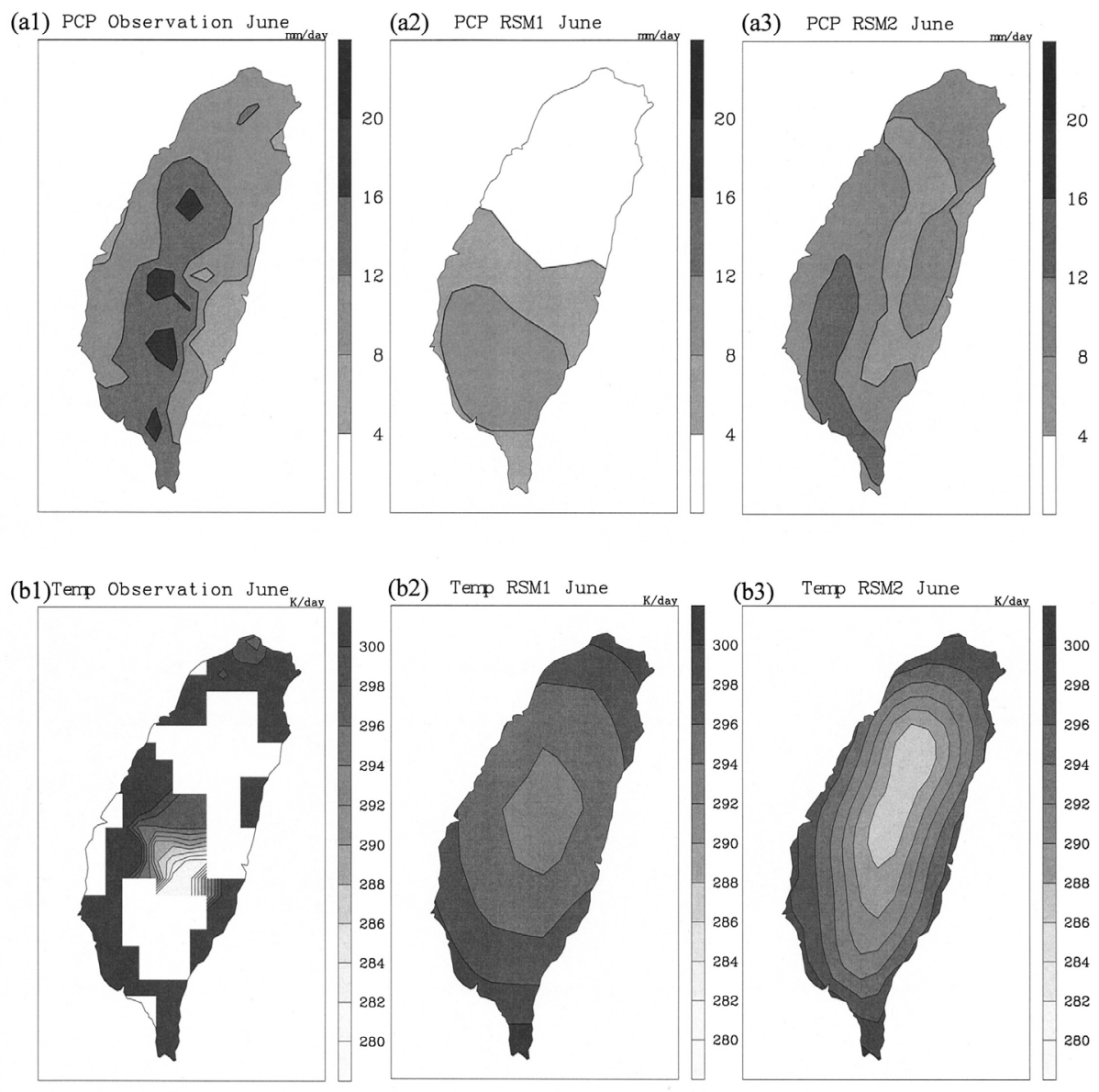

Fig. 8. June precipitation (a) and temperature (b) averaged over 1990 though 2000 of Taiwan for (1) observation, (2) RSM1, and (3) RSM2. The precipitation contour and shade intervals are $4 \mathrm{~mm} \mathrm{day}^{-1}$ and temperature intervals are $2 \mathrm{~K}_{\mathrm{day}^{-1}}$. 
more realistic model orography, surface temperature is better represented than in RSM1. The RSM runs in July and August (not shown) showed similar displacement, and also underestimated precipitation and temperature.

Figure 9 shows the time series of island-averaged June monthly mean precipitation for Taiwan from 1990 through 2000. The GPCP monthly-mean precipitation follows the surface station observed time series well, but is slightly under-estimated. Reanalysis and RSM1 also follow the observed time series, but with very weak inter-annual variability. RSM2, despite a weaker amplitude than the observations, does show improvement over reanalysis and RSM1, except for the first 3 years. Overall, it seems that the RSM2 precipitation demonstrates better results compared to observation than reanalysis and RSM1.

Cumulative percentages of the daily RSM1, RSM2, and reanalysis precipitation over Taiwan in June, along with station observations, are given in Fig. 10 to examine the distinct characteristics of precipitation. In this plot, the intercept at $1 \mathrm{~mm} \mathrm{day}^{-1}$ approximates the frequency of non-rainy days, and the slope indicates the percentage increment at a given rainfall intensity. The daily rainfall at all grid points lower than $1 \mathrm{~mm}^{-1}$ day $^{-1}$ in both RSM runs and observations occur about $55 \%$ of time, but only $38 \%$ in NCEP reanalysis. The cumulative percentage of reanalysis increases rather rapidly between the ranges of 2 and $7 \mathrm{~mm} \mathrm{day}^{-1}$, and reaches the saturation value $(100 \%)$ at about $20 \mathrm{~mm}^{-1} \mathrm{yy}^{-1}$, indicating nearly no rainy days with intensity higher than $20 \mathrm{~mm} \mathrm{day}^{-1}$. RSM simulations, on the other hand, gradually increase their percentages and stay relatively closer to observations with similar slopes. This

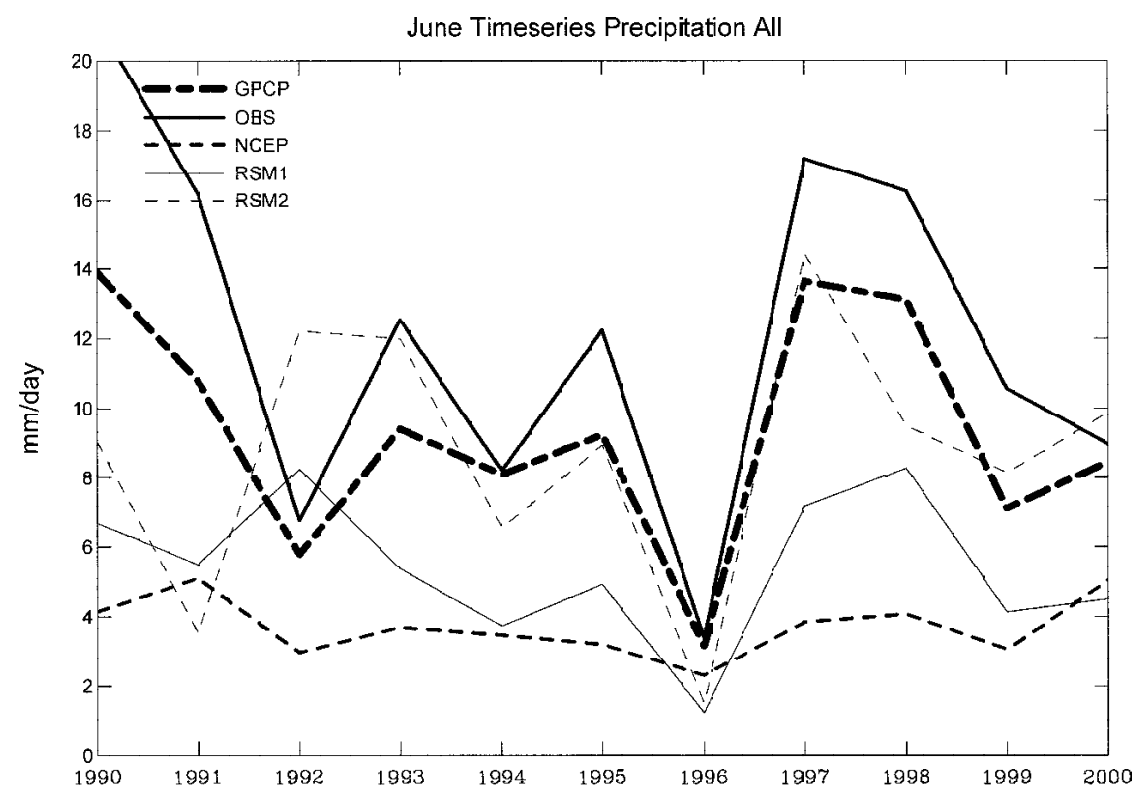

Fig. 9. Time series of island-averaged June seasonal-mean precipitation for GPCP; observation; NCEP reanalysis; RSM1, and RSM2. 


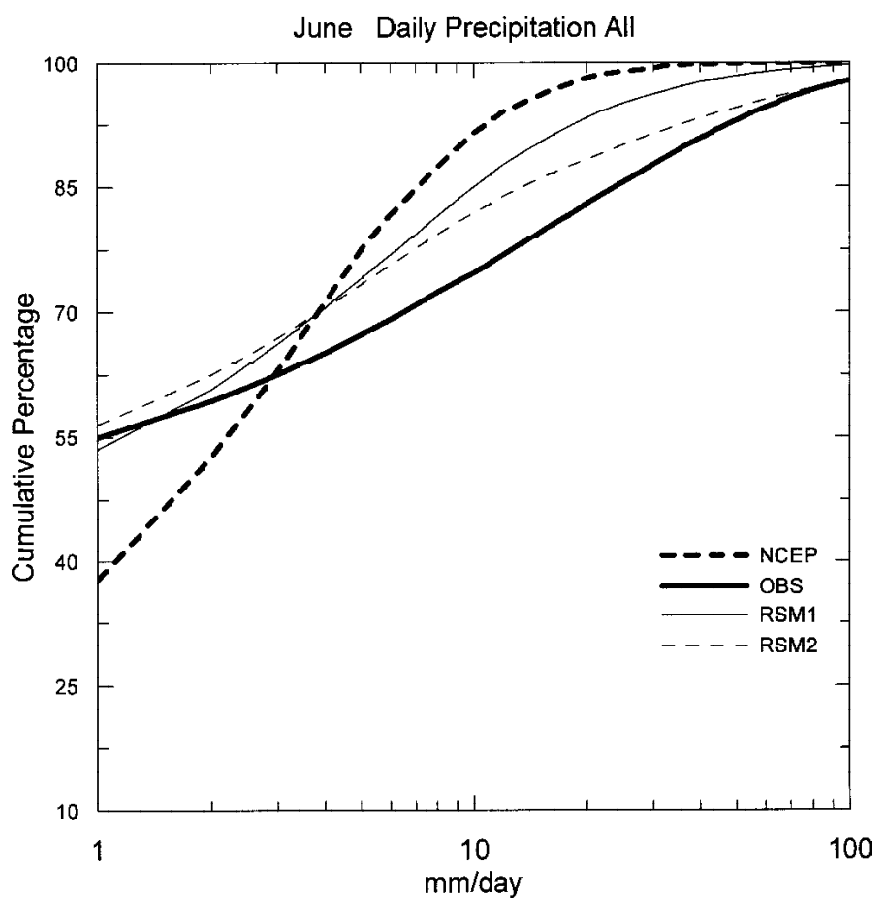

Fig. 10. Cumulative distribution function of daily precipitation in June for NCEP, station observation, RSM1, and RSM2. The threshold precipitation rate on the logarithmic abscissa is in units of $\mathrm{mm} \mathrm{day}^{-1}$.

suggests well-simulated precipitation behavior, especially in both the low and heavy rainfall events when compared to that of reanalysis, which shows mostly light rainfall events.

In the July time series of island-averaged precipitation for Taiwan (Fig. 11), RSM2 show a similar precipitation tendency as well as underestimated amplitude as RSM1, and both appear to be worse than reanalysis when compared to the station observations. Since RSM2 was forced by RSM1 circulation, the area-mean precipitation of the former should follow that of the latter. When the RSM1 area-mean precipitation does not show good correlation with observation, neither does that of RSM2. This simulation defect might be a consequence of the large-scale biases shown in Figs. 2, 3. While the Mei-Yu-type frontal system gradually moves away from Taiwan in July, the observed southwesterlies were replaced by simulated southeasterlies. The warm and moist southeasterly wind is thus partially blocked by the Central Mountain Range from entering the supposedly convection-active southwestern plain of Taiwan.

In cumulative frequency (Fig. 12), for an intensity range lower than $1 \mathrm{~mm} \mathrm{day}^{-1}$, the simulated and observed precipitation frequencies are not much different from each other. In spite of the improvement from the reanalysis, the defects of RSM simulations can still be seen clearly. At $10 \mathrm{~mm} \mathrm{day}^{-1}$, the observation has only $75 \%$ accumulated frequency, compared to 
90\% for RSMs. This means that most of the RSM simulated precipitation events had intensity lower than $10 \mathrm{~mm} \mathrm{day}^{-1}$. There were not enough heavy rainfall events, which were presumably convective-type, in the July simulations.

During August (Fig. 13), a climatologically typhoon-laden month, the time series of areamean precipitation for RSM2 follows observations, but were underestimated, similar to the forcing data of RSM1. Although, the RSMs show similar inter-annual precipitation variation in this typhoon month, these time-series plots reveal only the island-averaged precipitation. There are more distinct simulation differences over eastern and western Taiwan Island as described in the following.

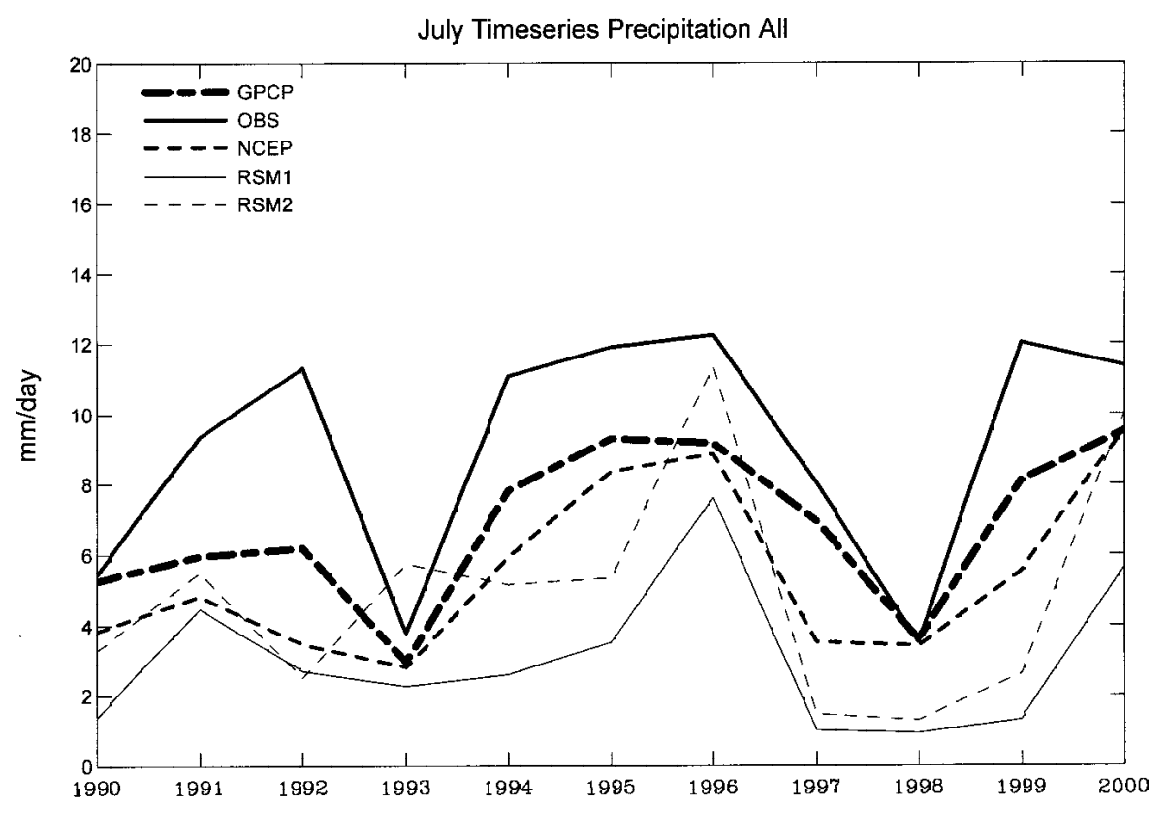

Fig. 11. Same as Fig. 9, except for July.

To understand how many local area features RSM captures, we separated Taiwan into 4 different areas, north (N), west (W), south (S), and east (E), as depicted in Fig. 1a. The areamean precipitation statistics, such as systematic error (SE), standard deviation (Std), and correlation coefficient with observation (Corr) were computed and shown in Table 2 for the months of June and August. SE is defined as the climatological deviation from the observational mean; Std is the area-mean of the temporal standard deviation from the monthly climatologies; Corr is computed as area-mean temporal correlation with that of observations. In general, although RSMs improve the SE and Std, the coarse NCEP reanalysis still has better correlation than the RSMs. Nevertheless, over southern and eastern regions, the RSMs still have significant correlation coefficient for simulations in June. For July (not shown) and August, the RSM shows the inverse pattern of correlation coefficient over 4 areas compared to those in June. During 


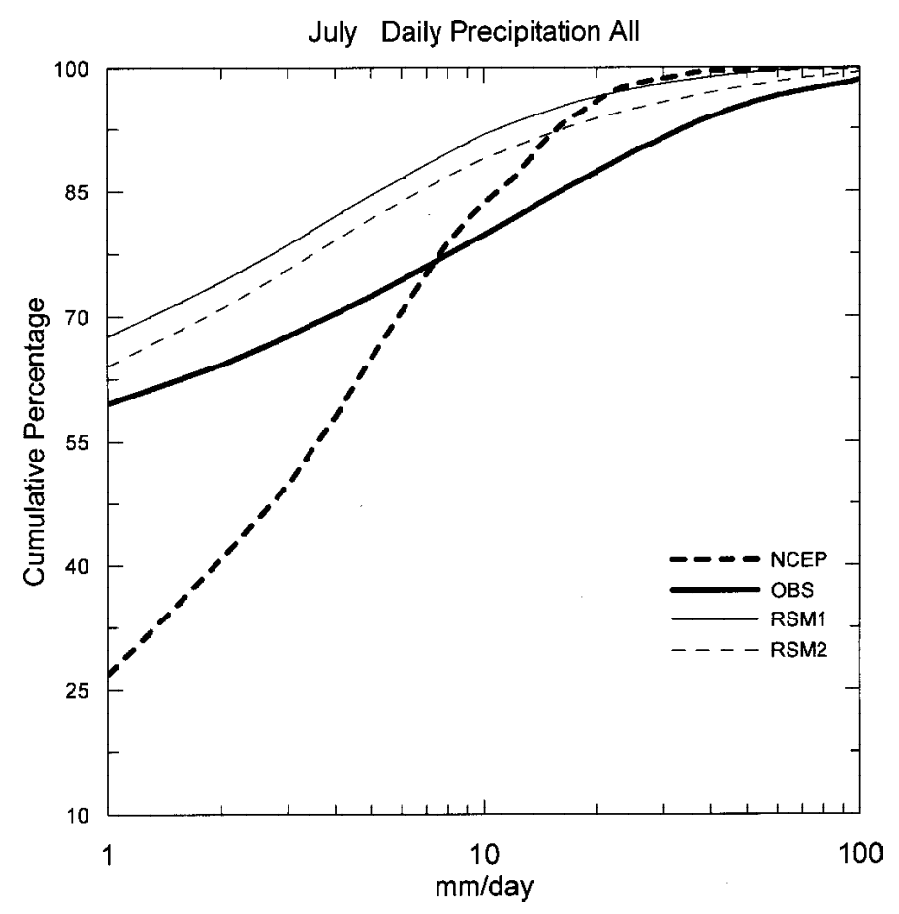

Fig. 12. Same as Fig. 10, except for July.

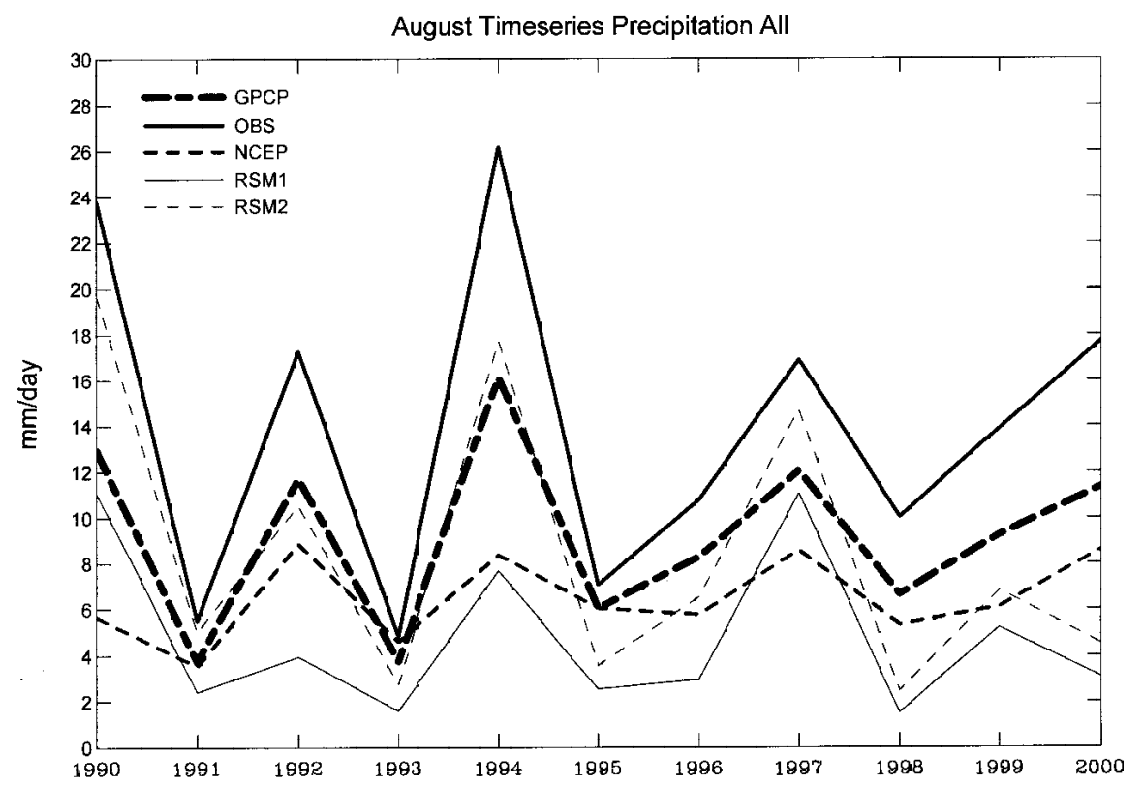

Fig. 13. Same as Fig. 9, except for August. 
Table 2. June and August monthly-mean precipitation statistics over the Taiwan area for area mean (Mean, $\mathrm{mm} \mathrm{day}^{-1}$ ), systematic error (SE, $\mathrm{mm}$ day $^{-1}$ ), standard deviation (Std., $\mathrm{mm} \mathrm{day}^{-1}$ ), and temporal correlation coefficients. (Corr.)

\begin{tabular}{|c|c|c|c|c|}
\hline \multicolumn{5}{|c|}{ JUN } \\
\hline N.Taiwan & Mean & $\mathrm{SE}$ & Std. & Corr. \\
\hline OBS & 10.0 & & 17.1 & \\
\hline NCEP & 3.01 & -7.0 & 4.99 & 0.47 \\
\hline RSM1 & 2.25 & -7.8 & 5.67 & 0.35 \\
\hline RSM2 & 9.28 & -0.7 & 21.9 & 0.31 \\
\hline \multicolumn{5}{|c|}{ JUN } \\
\hline S.Taiwan & Mean & $\mathrm{SE}$ & Std. & Corr. \\
\hline OBS & 13.4 & & 25.8 & \\
\hline NCEP & 4.09 & -9.3 & 5.25 & 0.61 \\
\hline RSM1 & 9.32 & -4.1 & 18.7 & 0.58 \\
\hline RSM2 & 11.8 & -1.6 & 29.8 & 0.43 \\
\hline
\end{tabular}

\begin{tabular}{|c|c|c|c|c|}
\hline \multicolumn{5}{|c|}{ JUN } \\
\hline W.Taiwan & Mean & $\mathrm{SE}$ & Std. & Corr. \\
\hline OBS & 12.6 & & 22.4 & \\
\hline NCEP & 3.35 & -9.2 & 5.07 & 0.58 \\
\hline RSM1 & 4.37 & -8.2 & 8.64 & 0.44 \\
\hline RSM2 & 9.79 & -2.8 & 25.5 & 0.37 \\
\hline \multicolumn{5}{|c|}{ JUN } \\
\hline E.Taiwan & Mean & $\mathrm{SE}$ & Std. & Corr. \\
\hline OBS & 12.2 & & 23,5 & \\
\hline NCEP & 3.76 & -8.4 & 5.14 & 0.62 \\
\hline RSM1 & 5.52 & -6.6 & 8.07 & 0.57 \\
\hline RSMZ & 8.30 & -3.8 & 18.0 & 0.50 \\
\hline
\end{tabular}

AUG

\begin{tabular}{|c|c|c|c|c|}
\hline N.Taiwan & Mean & SE & Std. & Corr. \\
\hline OBS & 11.8 & & 28.4 & \\
\hline NCEP & 6.10 & -5.7 & 6.93 & 0.63 \\
\hline RSM1 & 3.53 & -8.3 & 11.9 & 0.37 \\
\hline RSM2 & 7.47 & -4.3 & 20.4 & 0.48 \\
\hline
\end{tabular}

\begin{tabular}{|c|c|c|c|c|}
\hline S.Taiwan & Mean & SE & Std. & Corr. \\
\hline OBS & 17.5 & & 33.4 & \\
NCEP & 6.72 & -10. & 6.93 & 0.56 \\
\hline RSM1 & 6.85 & -10 & 14.5 & 0.31 \\
\hline RSM2 & 10.7 & -6.7 & 23.5 & 0.24 \\
\hline
\end{tabular}

AUG

\begin{tabular}{|c|c|c|c|c|}
\hline W.Taiwan & Mean & SE & Std. & Corr. \\
\hline OBS & 12.2 & & 27.1 & \\
\hline NCEP & 5.80 & -6.4 & 6.28 & 0.49 \\
\hline RSM1 & 3.05 & -9.2 & 6.21 & 0.38 \\
\hline RSM2 & 8.34 & -3.8 & 23.6 & 0.45 \\
\hline
\end{tabular}

\begin{tabular}{|c|c|c|c|c|}
\hline E.Taiwan & Mean & SE & Std. & Corr. \\
\hline OBS & 14.0 & & 31.4 & \\
\hline NCEP & 6.53 & -7.5 & 6.86 & 0.62 \\
\hline RSM1 & 5.14 & -8.9 & 9.23 & 0.22 \\
\hline RSM2 & 7.90 & -6.1 & 16.3 & 0.28 \\
\hline
\end{tabular}

these two months, RSM2 shows better correlation in the north and west, but poorer correlation in the south and east. This is due to poor simulation of heavy convective rainfall over southern and eastern Taiwan during this time of the season. The RSMs obviously did not capture these features well. Overall, the RSM simulations show mixed skills over various areas. The geographical and seasonal dependence in skill is likely due to the distinct types of precipitation which might not be properly captured in the RSM simulations.

Many previous studies (e.g., Elsberry 1990; Wu and Kuo 1999; Lin et al. 2002; Wu et al. 2002) pointed to the problem of simulating heavy typhoon precipitation over Taiwan Island. Although monthly mean precipitation shows a good interannual variation in island averaged precipitation, the daily precipitation time series (not shown) demonstrates that daily precipitation simulations are actually not very accurate, especially during typhoon cases. To identify 
the skill of RSM in simulating typhoon days we separated all days in August from the 11 years simulation into two groups, typhoon days and non-typhoon days. For a definition of typhoon days we refer to the CWB (http://www.cwb.gov.tw). Basically, the CWB typhoon days are defined when a typhoon is within a 100-km radius to any point on Taiwan Island. Figure 14 shows the composite sea level pressure between reanalysis and RSM runs. The reanalysis demonstrates a well defined low pressure center over Taiwan during typhoon days. However, the corresponding low pressure center and intense pressure gradient are poorly simulated in the RSM. Consequently, the strong cyclonic circulation centered over Taiwan is vague in the simulation. This defect could be due to the inability of RSM in simulating extreme low-pressure systems. Recently a "bogus" typhoon method has been proposed to properly solve this problem in regional modeling (e.g., Ahn and Lee 2002; Lee et al. 2004). During non-typhoon days, the reanalysis displaces the lower pressure center to South China, but RSM2 still did not simulate this lower pressure center well. It appears that the simulated subtropical high is too strong. In other words, this result is the same as that in Fig. $2 b$ for non-typhoon simulation in June.

(a) Reanalysis ( $\mathrm{Ty}$ )

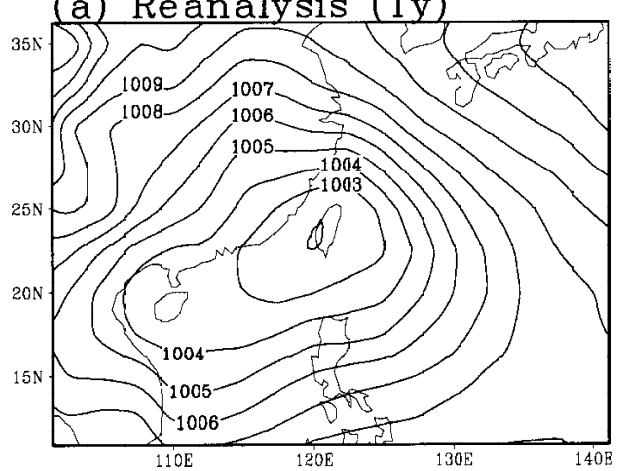

(c) Reanalysis (NTy)

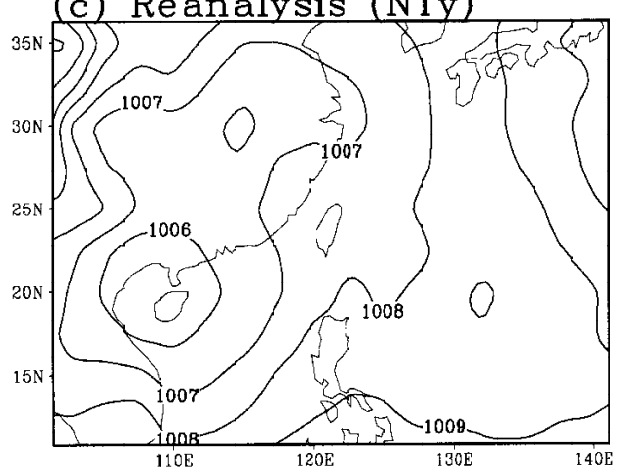

(b) RSM 1 (Ty)

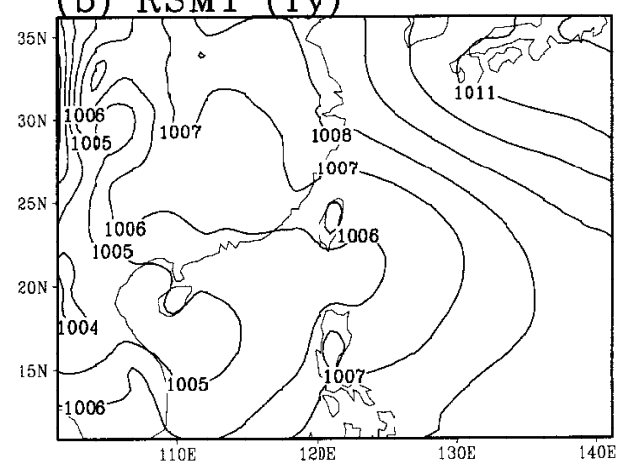

(d) RSM1 (NTy)

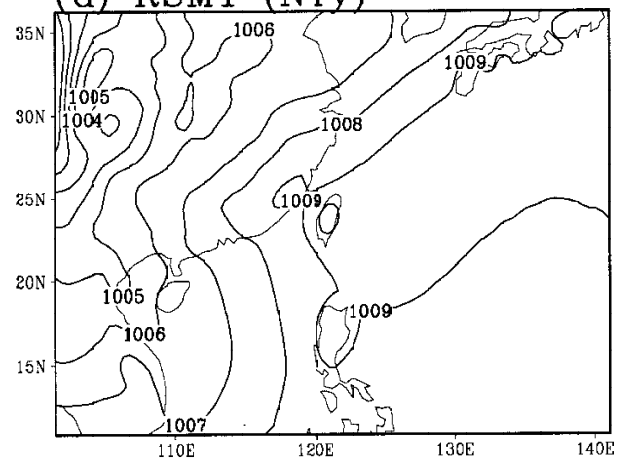

Fig. 14. August sea level pressure 11-years averaged during typhoon days (a, b) and non-typhoon days (c, d) from NCEP reanalysis (a, c) and RSM1 (b, d). The contour intervals are 1-hPa. 
Figure 15 shows the composite precipitation of NCEP reanalysis and RSM simulation August precipitation during typhoon and non-typhoon days from 1990 though 2000. It is shown that heavy rainfall over the western Pacific during typhoon days can be found in reanalysis, but this heavy precipitation area splits into two relatively weak centers over the offshore eastern Taiwan and northeastern Philippine areas. Only the heavy precipitation center over the Philippines was simulated by RSM, in addition to a rather weak oceanic center to its left. On the other hand, the non-typhoon precipitation composite of reanalysis and the RSM reveal no significant difference, except the RSM results in more local precipitation features over land and less precipitation over the ocean. Overall, the RSM simulated heavy rainfall features during typhoon days poorly, but the simulation quality might be somewhat acceptable during non-typhoon days in August, at least as good as those in June or even in July. The inability of the RSM and the acceptability of reanalysis composite precipitation over the Taiwan area can be best demonstrated in Fig. 16. Here the August typhoon-day precipitation composite from 1997 though 2000 of GPCP (1.0 ${ }^{\circ}$ resolution), NCEP reanalysis, and the RSM runs are shown.

(a) Reanalysis (Ty)
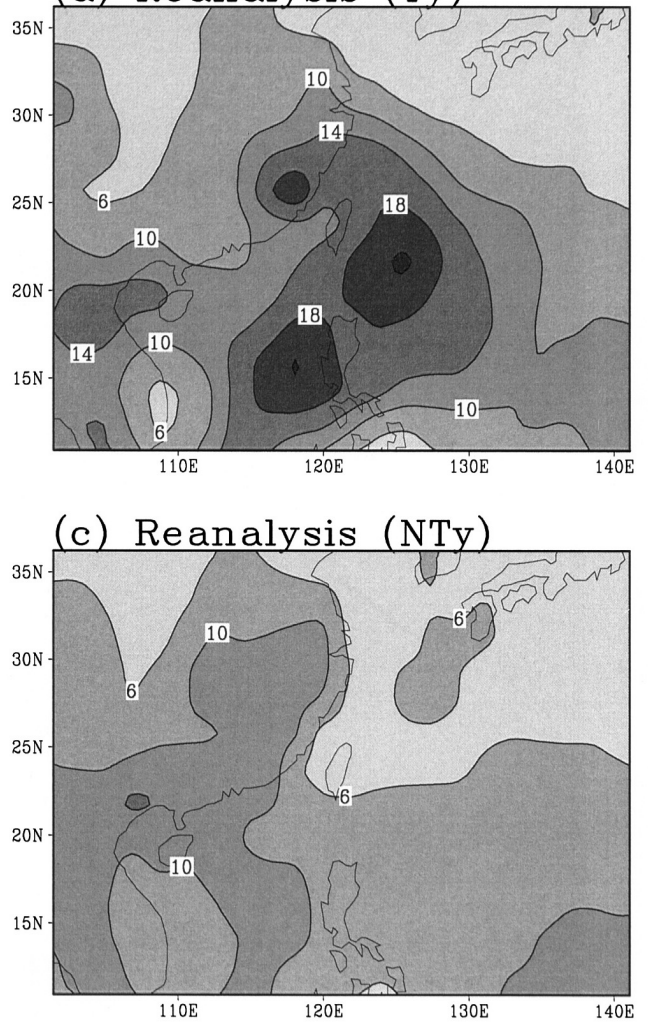

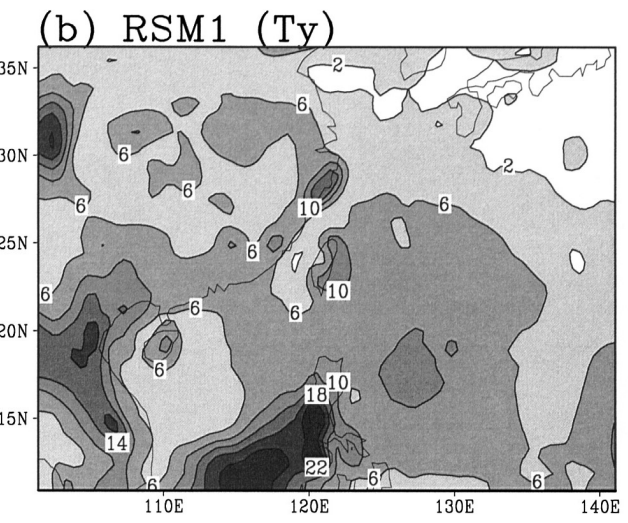

(d) RSM1 (NTy)

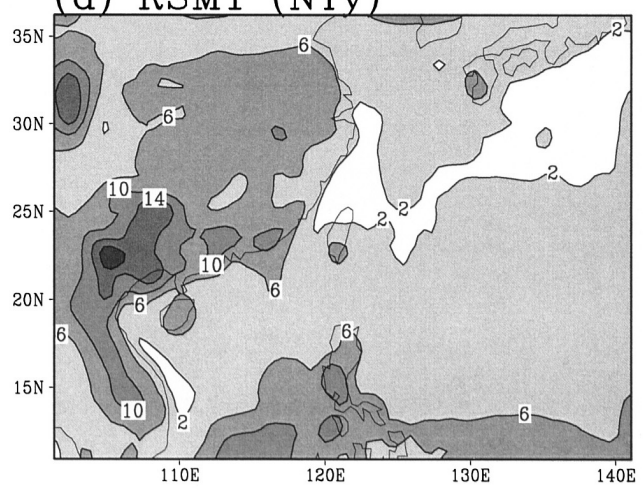

Fig. 15. Same as Fig. 14, except for precipitation with contour and shading intervals of $4 \mathrm{~mm} \mathrm{day}{ }^{-1}$. 
The GPCP precipitation reveals a rainfall maximum covering Taiwan, Philippines and the South China Sea. A similar pattern can also be seen in the reanalysis, but the rain band is extended in the north-south direction. Similar to Fig. 15, the RSM1 composite demonstrates the same simulation defect.

On a 15-km local scale, Fig. 17 shows the August composite precipitation during typhoon days and non-typhoon days for observations and RSM2 simulation. There is heavy observed rainfall over East Taiwan, where typhoons most likely landed, with an amount of precipitation intensity more than $40 \mathrm{~mm} \mathrm{day}^{-1}$. However, the RSM completely missed these events and resulted in rather weak rainfall centers over southwestern and northern Taiwan. This inability can be further examined when compared with non-typhoon days' simulation (Figs. 17c and d). In non-typhoon days, the maximum precipitation center over southwestern Taiwan was captured in RSM2, although the amount of precipitation was rather weak. This defect may be partly inherited from RSM1 simulation and may be partly attributable to the heavy smoothing
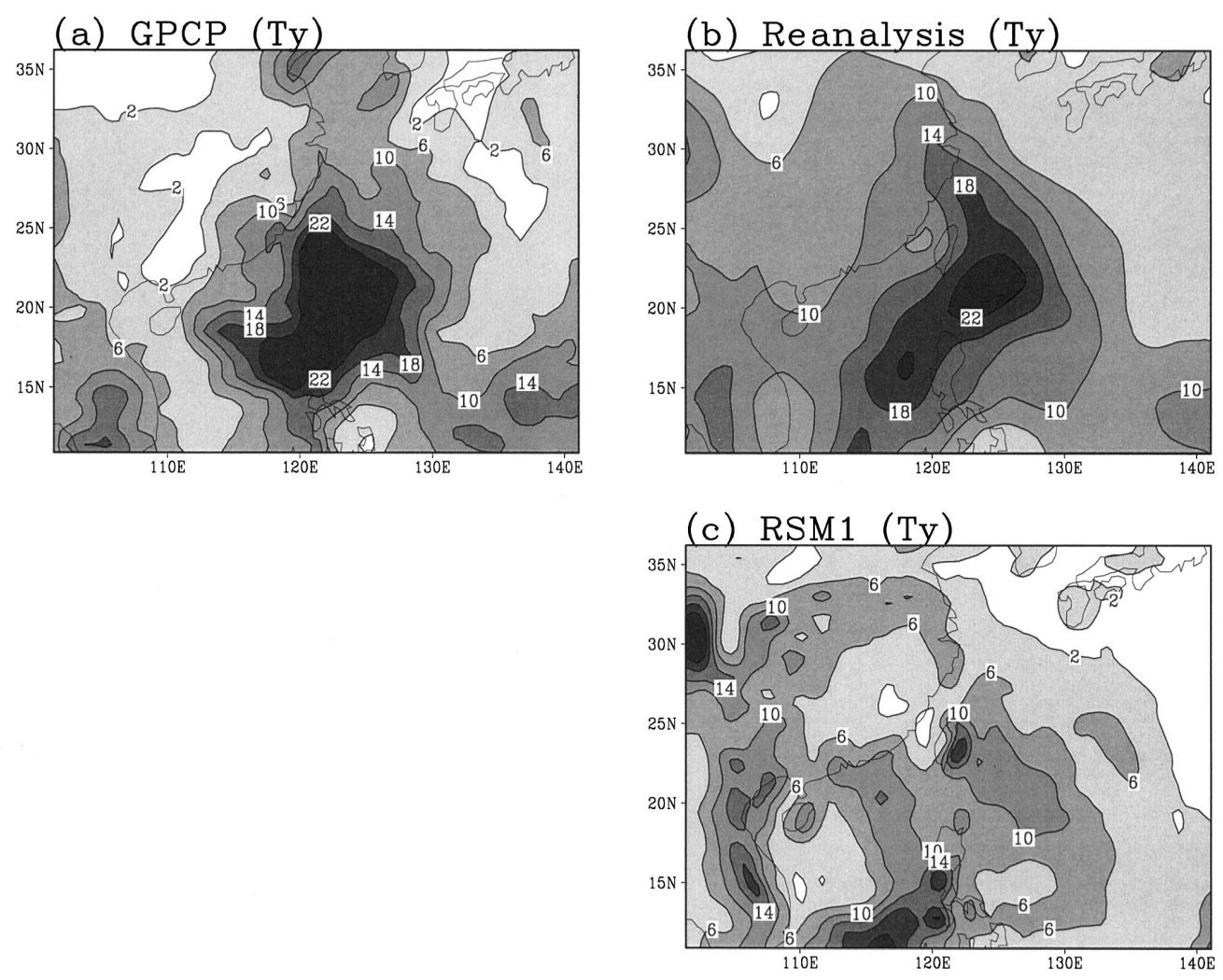

Fig. 16. Typhoon days' precipitation composite in August averaged from 1997 through 2000 for (a) GPCP; (b) NCEP reanalysis, and (c) RSM1. Contour and shading intervals are $4 \mathrm{~mm} \mathrm{day}^{-1}$. 
(a)

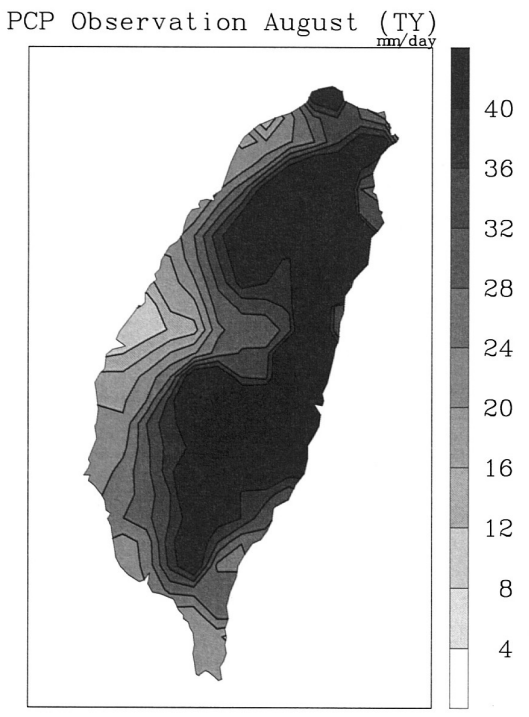

(c)

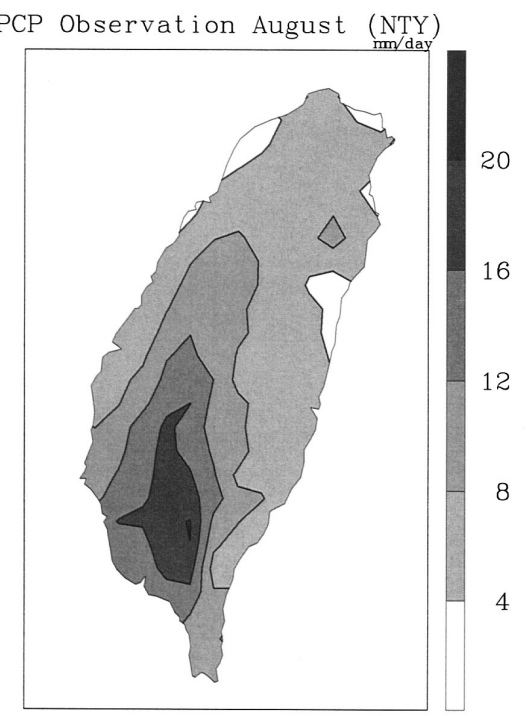

(b) PCP RSM2 August (TY)

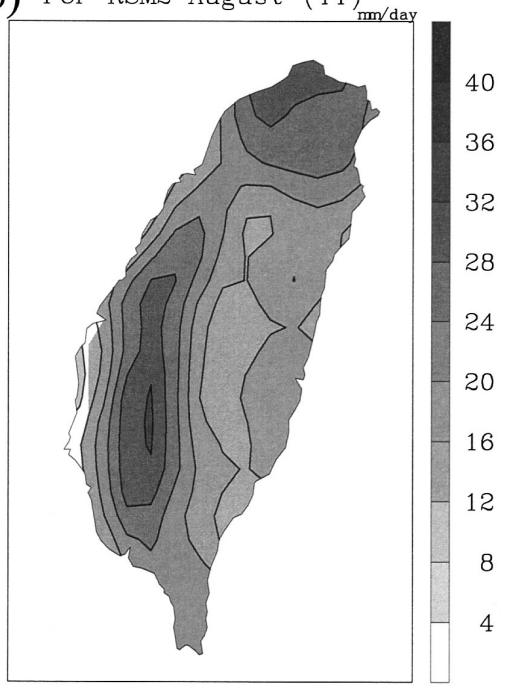

(d) PCP RSM2 August (NTY)

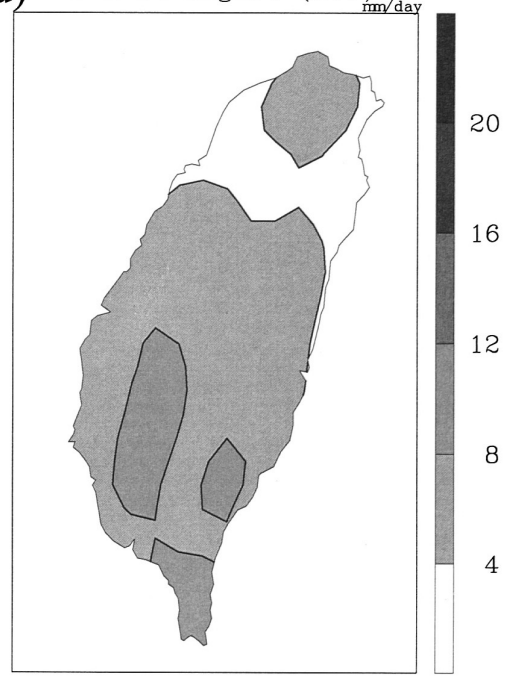

Fig. 17. Typhoon days' precipitation composite $(\mathrm{a}, \mathrm{b})$ and that for non-typhoon days $(c, d)$. Station observations are in $(a, c)$ and RSM2 in $(b, d)$. The contour and shading intervals are $4 \mathrm{~mm} \mathrm{day}^{-1}$.

of the model diffusion scheme. In summary, RSM precipitation simulation was acceptable during August non-typhoon days, but failed to simulate typhoon induced heavy rainfall, which unfortunately contributes significantly to the monthly mean value over Taiwan. 


\section{DISCUSSIONS AND SUMMARY}

A regional modeling experiment was developed to study the summertime climatology over Southeast Asia and Taiwan. Two RSM resolution setups, $50 \mathrm{~km}$ (RSM1) and $15 \mathrm{~km}$ (RSM2) respectively, were used. The simulated summertime sea level pressure pattern was similar to reanalysis, but the subtropical high was too intense. Consequently, a strong southerly circulation over southern China and Taiwan areas was induced. These patterns lead to strong inland flow over southeastern China and were partly related to the overestimated RSM precipitation in this region.

Although the precipitation pattern in reanalysis is generally similar to that of GPCP, there is a high bias over China and an oceanic low bias over the Pacific. While the RSM large-scale simulation appeared to be similar to reanalysis and showed more detailed precipitation over local land areas, it also inherited many defects from the driving reanalysis. Despite this, the RSM captures terrain-induced local strong precipitation centers, which are usually missed in coarser resolution models. There are also large-scale systematic biases in the regional simulations. The simple removal of the systematic bias a posteriori by removing the precipitation difference between observation and reanalysis only improved the RSM precipitation amount a little over southeastern China. There is still a low bias over the ocean when compared to GPCP. Large-scale bias post-processed removal such as that proposed by Chen (2002), or the interactive large-scale damping by Kanamaru and Kanamitsu (2004) should be used for future experiments.

At local scale over the Taiwan area, it is shown that RSM2 simulated precipitation patterns were acceptable. However, the amount was underestimated over the mountaintop. This defect is likely attributable to the second order over-smoothed diffusion scheme at pressure surface (Juang et al. 2005). For precipitation cumulative percentage, it is shown that the RSM2 simulation has more light-rain or dry days during summer, and it is reasonably simulated compared to reanalysis and RSM1. In the 11-year island-averaged monthly precipitation time series of Taiwan, RSM2 captured the observed inter-annual variability for June and August, but not for July.

Despite the ability of the RSM in simulating the island-averaged precipitation temporal variability, the simulated regional distributions were incorrect for August. The temporal correlation coefficient degenerated moving from June into August, especially for southern and eastern Taiwan, where most heavy rainfall came from typhoons. The composite sea-level-pressure and precipitation revealed that during the typhoon days in August RSM1 did not simulate the extreme-low pressure well, hence the heavy precipitation over these typhoon vulnerable regions of eastern and southern Taiwan were missing in the higher-resolution RSM2. In contrast, the non-typhoon days' composites showed RSM1 pressure to be better simulated, as was the precipitation compared to that of GPCP, despite a slightly high bias for the subtropical high. On a local scale, the RSM2 simulated precipitation center was well placed over southwestern Taiwan, exactly where it was observed during non-typhoon days, but with a weaker amplitude.

In simulating the summertime regional climate over this area, this study clearly indicates the inability of the RSM in two respects. First, the severe large-scale bias in the simulation of the subtropical high significantly affects the direction and the intensity of the prevailing 
monsoon. While this biased simulation might be inherited from the NCEP RSM model physics defects in simulating the tropical features, an ad hoc large-scale correction scheme such as that used in Kanamaru and Kanamitsu (2004), could potentially be an effective solution. The second problem is the inability of the RSM in simulating typhoons. Since the driving models cannot initialize the high-resolution RSM with a needed typhoon initial condition nor a perfect driving boundary condition, the "bogus" typhoon planting method might provide an alternative (Ahn and Lee 2002; Lee et al. 2004). While we will examine these correction methods in our future study, the limitation of these methods is that they can only be done in simulation, but not in prediction mode where no "perfect" large-scale and high-resolution initial condition would be available.

Acknowledgements This work is supported by the National Science Council of the Republic of China under Grants NSC 92-2111-M-002-009, NSC 93-EPA-Z-002-002, NSC 93-2111M-002-005 and NSC 93-2621-Z-002-008. This research was performed on a PC cluster provided by the Department of Atmospheric Science, National Taiwan University (NTU). We thank Ms. Diane Boomer for her excellent job in proofreading the manuscript. We also extend our thanks to two anonymous reviewers for their constructive and stimulating suggestions.

\section{REFERENCES}

Ahn, Y. I., and D. K. Lee, 2002: Impact of bogus tropical cyclones on summertime circulation in regional climate simulation.J. Geophys. Res., 107, 4303, doi:10.1029/2001JD000416.

Chen, S. C., J. O. Roads, H. M. H. Juang, and M. Kanamitsu, 1999: Global to regional simulations of California wintertime precipitation. J. Geophys. Res., 104, 31517-31532.

Chen, S. C., 2002: Model mismatch between global and regional simulations. Geophys. Res. Lett., 29, doi:10.1029/2001GL013570.

Chen, S. C., M. C. Wu, S. Marshall, H. M. H. Juang, and J. O. Roads, 2003: 2xCO 2 Eastern Asia Regional Responses in the RSM/CCM3 Modeling System. Global Planetary Change, 37, 277-285.

Chen, S. C., and J. O. Roads, 2004: Impact of the Soil Moisture on Regional Spectral Model Interannual Simulations for South America. (submitted to J. Hydromet.).

Chien, F. C., Y. H. Kuo, and M. J. Yang, 2002: Precipitation Forecast of MM5 in the Taiwan Area during the 1998 Mei-yu Season. Wea. Forecasting, 17, 739-754.

Elsberry, R. L., 1990: International Experiments to Study Tropical Cyclones in the Western North Pacific. Bull. Am. Meteor. Soc., 71, 1305-1316.

Hong, S. Y., and A. Leetmaa, 1999: An Evaluation of the NCEP RSM for regional climate modeling. J. Climate., 12, 592-609.

Hsu, H. H., and C. T. Chen, 2002: Observed and projected climate change in Taiwan.Meteor. Atmos. Phy., 79, 87-104.

Huffman, G. J., R. F. Adler, P. Arkin, A. Chang, R. Ferraro, A. Gruber, J. Janowiak, A. McNab, B. Rudolf, and U. Schneider, 1997: The Global Precipitation Climatology Project (GPCP) Combined Precipitation DataSet. Bull. Am. Meteor. Soc., 78, 5-20. 
Juang, H. M. H., and M. Kanamitsu, 1994: The NMC nested regional spectral model.Mon. Wea. Rev., 123, 3-26.

Juang, H. M. H., S. Hong, and M. Kanamitsu, 1997: The NMC nested regional spectral model. An update. Bull. Am. Meteor. Soc., 78, 2125-2143.

Juang, H. M. H., C. T. Lee, F. Zhang, Y. Song, M. C. Wu., Y. C. Chen, and S. C. Chen, 2005: Applying Horizontal Diffusion on Pressure Surface to Mesoscale Models on TerrainFollowing Coordinates. Mon. Wea. Rev., 133, 1384-1402.

Kalnay, E., and colleagues, 1996: The NCEP/NCAR 40-year Reanalysis project.Bull. Amer. Meteor. Soc., 77, 437-472.

Kanamaru, H., and M. Kanamitsu. 2004: Regional Downscaling of the 50-Year NCEP/NCAR Reanalysis for California and the United States. First An. Conf. Global Climate Change, $8 \mathrm{~A} 3$.

Lee, D. K., and M. S. Suh, 2000: Ten-year east Asian summer monsoon simulation using a regional climate model (RegCM2). J. Geophys. Res., 105, 29565-29577.

Lee D. K., Y. I. Ahn, and C. J. Kim, 2004: Impact of ocean roughness and bogus typhoons on summertime circulation in a wave-atmosphere coupled regional climate Model. $J$. Geophys. Res., 109, doi:10.1029/2003JD003781.

Liu, Y., F. Giorgi, and W. M. Washington, 1994: Simulation of Summer Monsoon Climate over East Asia with an NCAR Regional Climate Model. Mon. Wea. Rev., 122, 23312348.

Lin, Y. L., D. B. Ensley, S. Chiao, and C. Y. Huang, 2002: Orographic Influences on Rainfall and Track Deflection Associated with the Passage of a Tropical Cyclone.Mon. Wea. Rev., 130, 2929-2950.

Mitchell, T. D., T. R. Carter, P. D. Jones, M. Hulme, and M. New, 2004: A comprehensive set of high-resolution grids of monthly climate for Europe and the globe: the observed record (1901-2000) and 16 scenarios (2001-2100). J. Climate. (Submitted).

Nobre, P., A. D. Moura, and L. Sun, 2001: Dynamical downscaling of seasonal climate prediction over Nordeste Brazil with ECHAM3 and NCEP's regional spectral models at IRI. Bull. Am. Meteor. Soc., 82, 2787-2796.

Roads, J. O., S. C. Chen, and M. Kanamitsu, 2003: US regional climate simulations and seasonal forecasts. J. Geophys. Res., 108, 8606, doi:10.1029/2002JD002232.

Roads, J., S. Chen, S. Cocke, L. Druyan, M. Fulakeza, T. LaRow, P. Lonergan, J. H. Qian, and S. Zebiak, 2003: International Research Institute/Applied Research Centers (IRI/ ARCs) regional model intercomparison over South America.J. Geophys. Res., 108 (D14), 4425, doi:10.1029/2002JD003201.

Takle, E., W. J. Gutowski, R. W. Arritt, Z. Pan, C. J. Anderson, R. R. da Silva, D. Cayan, S. C. Chen, F. Giorgi, J. H. Christensen, S. Y. Hong, H. M. Juang, J. Katzfey, W. M. Lapenta, R. Laprise, G. E. Liston, P. Lopez, J. McGregor, R. A. Pielke Sr., and J. O. Roads, 1999: Project to intercompare regional climate simulations (PIRCS): Description and initial results. J. Geophys. Res., 104, 19443-19461.

Wu, C. C., and Y. H. Kuo, 1999: Typhoons Affecting Taiwan: Current Understanding and Future Challenges. Bull. Amer. Meteor. Soc., 80, 67-80. 
Wu, C. C., T. H. Yen, Y. H. Kuo, and W. Wang, 2002: Rainfall Simulation Associated with Typhoon Herb (1996) near Taiwan. Part I: The Topographic Effect. Wea. Forecasting, 17, 1001-1015.

Yeh, H. C., and Y. L. Chen, 1998: Characteristics of Rainfall Distributions over Taiwan during the Taiwan Area Mesoscale Experiment (TAMEX).J. Appl. Meteor., 37, 14571469. 